\title{
Traducción y adaptación transcultural instrumento Seguridad de Paciente en Administración de Medicamentos Pediatría: Versión español
}

\author{
Translation and cross-cultural adaptation of the instrument Patient Safety in Pediatric Drug Administration: \\ Spanish version \\ Tradução e adaptação transcultural do instrumento Segurança do Paciente na Administração de \\ Medicamentos na Pediatria: versão espanhola
}

Lilia Jannet Saldarriaga Sandoval ${ }^{1,2}$ [] Francisca Elisângela Teixeira Lima ${ }^{1}$ (C)

Sabrina de Souza Gurgel ${ }^{1}$ (])

Igor de Freitas ${ }^{1}$ (1)

Lorena Pinheiro Barbosa ${ }^{1}$ (1)

Paulo César de Almeida ${ }^{3}$ (D)

1. Universidade Federal de Ceará. Fortaleza, CE, Brasil.

2. Universidad Nacional de Tumbes. Tumbes, Perú.

3. Universidade Estadual de Ceará. Fortaleza, CE, Brasil.

\begin{abstract}
Resumen
Objetivo: Traducir, adaptar e validar el contenido del instrumento Seguridad del paciente en la Administración de Medicamentos en Pediatría versión portugués para el español en la realidad de Perú. Método: Estudio metodológico, a partir de las etapas: traducción inicial para idioma español por dos traductores independientes; síntesis de las traducciones; Retrotraducción de la síntesis del instrumento para el idioma de origen; test de la versión prefinal con tres enfermeras y evaluación de las propiedades psicométricas del instrumento en la versión español, de acuerdo validación de contenido y de confiabilidad. Fue aprobado por el comité de ética. Resultados: las etapas de traducción y retrotraducción por el comité de especialistas consolido las versiones y componentes del instrumento y las traducidas quedando la versión prefinal del instrumento para testar en la práctica asistencial después de realizadas modificaciones en la redacción de algunos ítems de la versión traducida. En el análisis de las propiedades psicométricas, el Coeficiente de validez de contenido obtenida por el comité de especialistas es adecuado $(>0,80)$, con Alfa de Cronbach final del instrumento de 0,91. Conclusión: el instrumento Seguridad del Paciente en la Administración de Medicamentos en Pediatría - versión español se encuentra traducido, adaptado, validado y adecuada confiabilidad.
\end{abstract}

Palabras clave: Seguridad del Paciente; Pediatria; Traducción; Adaptación, Atención de Enfermería.

\begin{abstract}
Objetive: Translate, adapt and validate the content of the instrument Patient Safety in the Administration of Medicines in Pediatrics Portuguese version for Spanish in the reality of Peru. Method: Methodological study, based on the steps: initial translation into Spanish by freelance translators; synthesis of translations; Back translation of the synthesis of the instrument to the origina language; test of the prefinal version with three nurses and evaluation of the psychometric properties of the PSAMP-Ev instrument, for precise content validation and reliability (homogeneity: Cronbach's Alpha) was started after approval by the Ethics Committee. Results: in the translation and back-translation steps by the expert committee, all versions and components of the instrument and all translated versions, and the pre-final version of the instrument has been developed for practice testing. After changes were made in the wording of some items of the translated version to simplify it grammatically and, in some cases, to adapt it to a more widely used language, aiming at better understanding by the target population. In the analysis of psychometric properties, The content validity coefficient obtained by the specialist committee is adequate $(>0.80)$, with the final Cronbach's Alpha of the instrument of 0.91. Conclusion: the instrument Patient Safety in the Administration of Medicines in Pediatrics - english version is translated, adapted, validated and adequate reliability.
\end{abstract}

Keywords: Patient Safety; Pediatrics; Translating; Adaptation, Nursing Care.

\section{Resumo}

Objetivo: Traduzir, adaptar e validar o conteúdo do instrumento Segurança do Paciente na Administração de Medicamentos em Pediatria versão em português para o espanhol na realidade do Peru. Método: Estudo metodológico, baseado nas etapas: tradução inicial para o espanhol por tradutores autônomos; síntese de traduções; Retrotradução da síntese do instrumento para o idioma original; teste da versão pré-final com três enfermeiras e avaliação das propriedades psicométricas do instrumento SPAMP-vE, para validação precisa do conteúdo e confiabilidade (homogeneidade: Alfa de Cronbach), foi iniciado após aprovação pelo Comitê de Ética. Resultados: nas etapas de tradução e retrotradução pelo comitê de especialistas consolidou-se todas as versões e componentes do instrumento, incluindo o instrumento original, instruções e todas as versões traduzidas, e se desenvolveu a versão prefinal do instrumento para testes na prática assistencial. No processo de equivalência semântica, idiomática y conceptual foi enfatizada a influência do nível sociocultural e profissional na compreensão das questões do instrumento pelo público-alvo. Assim, foram realizadas modificações na redação de alguns itens da versão traduzida para simplificá-la gramaticalmente e, em alguns casos, para adequá-la a uma linguagem mais utilizada, visando melhor compreensão pela população-alvo. Na análise das propriedades psicométricas, o Coeficiente de Validade de conteúdo obtida pelo comitê de especialistas foi adequada $(>0,80)$, com Alfa de Cronbach final do instrumento de 0,91. Conclusão: o instrumento Segurança do Paciente na Administração de Medicamentos na Pediatria - versão espanhol encontra-se traduzido e adaptado, apresentando validade e confiabilidade adequadas.

Palavras-chave: Segurança do paciente; Pediatria; Tradução; Adaptação, Cuidados de Enfermería. 


\section{INTRODUCCIÓN}

El sistema de medicación es compuesto por un conjunto de procesos que son interconectados, interdependientes e interdisciplinares, que tienen como objetivo proporcionar atención médica con calidad, efectividad y seguridad al paciente. Se constituye de seis etapas, a saber: prescripción médica, dispensación, preparación del medicamento, administración del medicamento y monitorización del paciente. ${ }^{1}$

La preparación y administración de la medicación, el monitoreo, registro del procedimiento realizado y de posibles quejas/ reacciones adversas presentadas por el paciente comprenden la oportunidad final de interceptar errores derivados de los otros procesos del sistema, causando perjuicio a aproximadamente a 1,3 millones de individuos anualmente. . $^{2,3}$ Una vez que el equipo de enfermería es responsable de la parte final de ese sistema, su actuación se torna crucial para evitar errores que puedan hacer algún tipo de daño al paciente asistido. ${ }^{4}$

La administración de medicamentos en pediatría es una de las actividades más complejas, debido a los errores o casi errores que son más frecuentes en niños hospitalizados de lo que en adultos. Por lo tanto, los profesionales que preparan y administran medicación deben tener acciones de seguridad en el procedimiento, desde la manipulación del medicamento hasta el momento de ejecutar la técnica en el paciente. .,6 $^{5,6}$

Al respecto, en el estudio de 500 prescripciones en los servicios pediátricos, el 37,4\% tiene una acción incorrecta (indicación ilegible, no señalaba dosis, vía o frecuencia de administración), el 16,2\% dos acciones incorrectas, el 11,0\% tres acciones incorrectas y el $4,4 \%$ de las prescripciones todas las acciones fueron incorrectas. ${ }^{7}$

Estudio multicéntrico español para la Prevención de Errores de Medicación, estima que hay una media de 17 errores diarios por cada 100 pacientes hospitalizados relacionados con el sistema de medicación (el 16\% en prescripción, el 27\% en transcripción/ validación, el $48 \%$ en dispensación y el $9 \%$ en administración), de los cuales el $85 \%$ afectó al paciente y el $0,35 \%$ causo daño ${ }^{8}$

Teniendo en consideración que la seguridad del paciente se define como la reducción, a un mínimo aceptable, del riesgo de hacer daño desnecesario asociado al cuidado de la salud, ${ }^{7}$ que al estar bajo el cuidado de enfermería, puede abarcar una amplia variedad de posibles fallas involucradas en cada una de las etapas del proceso de la administración de la medicación. ${ }^{9}$

Así, el interés de utilizar tecnologías validadas y confiables que evalúen el proceso de la administración de medicamentos en los responsables, para ser utilizado en realidades que todavía no fueron exploradas, como en el caso el Perú, se procedió de hallazgos que indican que entre los errores de medicación existentes en pediatría, la mayoría es de administración, siendo la dosis incorrecta el tipo de error más frecuente, seguida por la omisión de medicación y por la medicación administrada en el momento incorrecto. ${ }^{10}$

El estudio se justifica porque el uso de herramientas representa un enfoque apropiado para mejorar la seguridad del paciente y promoverá: la seguridad del niño en el uso de medicamentos en establecimientos de salud; la revisión de un proceso de alto riesgo para pacientes pediátricos; la identificación de los puntos frágiles para proponer mejoras y correcciones, utilizando el instrumento SPAMP; buenas prácticas en todas las etapas del proceso de administración de medicamentos; estandarización de las acciones, capaces de habilitar una asistencia segura al paciente en las instituciones de salud en Perú.

También se resalta, que en Perú, existe una notable falta de estudios de validación de instrumentos, por esta razón, la adaptación transcultural es la mejor opción para los instrumentos de evaluación, permitiendo su aplicabilidad en cualquier país, cultura e idioma. Resaltándose que los estudios de traducción y adaptación facilitan la comparación de los resultados de un mismo instrumento en diferentes países y culturas, especialmente en el campo de la promoción de la seguridad del paciente en la administración de medicamentos. ${ }^{11}$

Por lo tanto, ante la inexistencia de un instrumento en español, para uso en el Perú que evalúe las acciones de la seguridad del paciente en la administración de medicamentos en pediatría en el ambiente hospitalario, se seleciono el instrumento Seguridad del Paciente en la Administración de Medicamentos en Pediatría (SPAMP), confiable en el idioma portugués, porque en la etapa de validación de contenido alcanzo resultados adecuados en el índice de validez de contenido (IVC) en pertinencia práctica $(0,775)$, clareza $(0,760)$ y relevancia $(0,938)$, obteniéndose la versión final del instrumento en portugués formado por 28 ítems. El alfa de Cronbach fue de 0,851 indicando una alta consistencia interna. La etapa de validación clínica identifica que los profesionales refirieron desarrollar satisfactoriamente 19 acciones, ${ }^{12}$

Además se, opta utilizar el Instrumento de Seguridad del Paciente en la Administración de Medicamentos Pediátricos (SPAMP) porque sigue las recomendaciones del Protocolo de Seguridad para la Prescripción, Uso y Administración de Medicamentos que el Ministerio de Salud ${ }^{13}$ de Brasil tiene implementado en el marco de las acciones desarrolladas para seguridad del paciente en las instituciones de salud, dicho instrumento fue construido y validado en pediatría en el idioma portugués de Brasil, ${ }^{12}$ pero precisa ser traducido para el español y adaptado para ser insertado en el contexto peruano.

Con base en lo expuesto, se tuvo como objetivo traducir, adaptar y validar el contenido del instrumento Seguridad del paciente en la Administración de Medicamentos en Pediatría versión portugués para el español en la realidad cultural del Perú.

\section{MÉTODO}

\section{Diseño del estudio}

Estudio metodológico que se propuso traducir y adaptar el instrumento de Seguridad del Paciente en la Administración de Medicamentos en Pediatría (SPAMP) para el idioma español del Perú. Para el desarrollo del estudio fueron seguidas cinco etapas referentes a la traducción adaptación de instrumentos se opto por las diretrizes sugeridas por Beaton et al., ${ }^{14}$ que 
consisten en: 1) traducción inicial;2) síntesis de las traducciones; 3) Retrotraducción al idioma de origen; 4) revisión por comité de especialistas; y 5) test de la versión prefinal (Figura 1).

\section{Procedimiento}

La primera etapa consistió en la elaboración de dos traducciones independientes (T1 e T2) para el idioma español. La traducción T1 fue elaborada por una enfermera nativa de Perú bilingue en portugués y español, teniendo más de 20 años de experiencia en la docencia universitaria. La profesional fue informada sobre conceptos y objetivos del estudio y su traducción tuvo como finalidad adquirir equivalencia en la perspectiva clínica peruana. El traductor responsable de la elaboración de la traducción T2 fue un profesor peruano, vinculado al centro de idiomas de la Universidad Nacional de Tumbes, del Perú, con dominio en los idiomas portugués y español. Este traductor no tuvo aclaraciones de los objetivos de la investigación, estando así más sensible a la detección de diferencias sutiles entre significados de términos o frases en el proceso de traducción para el idioma español.

La segunda etapa, síntesis de las traducciones, se dio a partir de las traducciones iniciales T1 y T2, que fueron sintetizadas por una tercera persona y reunidas en un único instrumento (T12). Los ítems de esta versión síntesis fueron evaluados con base en el análisis de los términos más próximos del instrumento original, identificando convergencias y divergencias de las traducciones y logrando unificar una versión preliminar del instrumento. ${ }^{14} \mathrm{La}$ versión T12 fue elaborada por una enfermera formada en el Brasil con doble nacionalidad (chilena y brasileña) y bilingue (portugués y español), con experiencia en pediatría y seguridad del paciente.

La tercera etapa, Retrotraducción al idioma original, se dio a partir de la versión T12, habiendo sido desarrollada por dos retro traductores aclarados acerca de los objetivos del instrumento. El primer retro traductor fue brasileño, profesor universitário de idioma español y con, mas de cinco años de docencia en el idioma. La segunda retro traducción fue elaborada por una enfermera brasileña bilingue en el idioma español, profesora universitaria en el Brasil con más de 30 años y con vasta experiencia de estudios de traducción y validación. En esta etapa fueron elaboradas las versiones retrotraduzidas independientes RT1 e RT2, totalmente a ciegas de la versión original.

En la cuarta etapa, para la revisión por un comité de nueve especialistas, examino las versiones producidas hasta entonces (T1, T2, T12, RT1 e RT2), además de la versión original del instrumento SPAMP-versión portugués. Así, fue compuesto por los cuatro traductores (dos de la traducción y dos de la retro traducción); sintetizador de la traducción; sintetizador del back translation; un doctor en linguística aplicada y metodologista

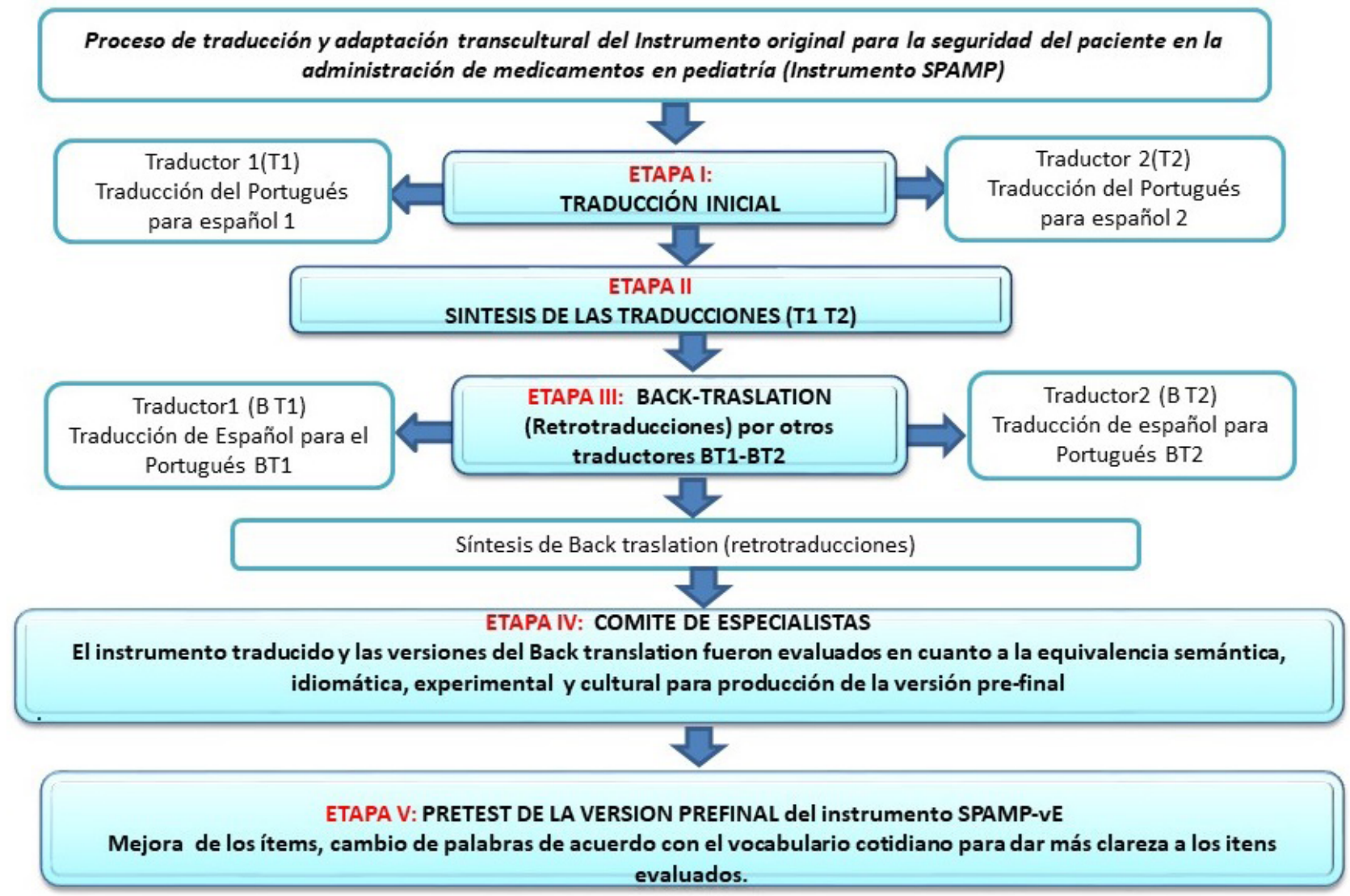

Figura 1. Representación gráfica del proceso de traducción y adaptación transcultural del instrumento SPAMP. Fuente: Propio autor basado en Beaton et al. ${ }^{14}$ 
un profesor con domínio en el idioma español y cinco años de experiencia en el área de linguística y una enfermera con experiencia en el área de pediatría y cinco años de experiencia en el área de linguística. ${ }^{11}$ Todos tienen dominio en portugués y español.

El comité formado fue responsable de la evaluación de las equivalencias semánticas (evaluación gramatical y de vocabulario), idiomática (expresiones equivalentes para el español), experimental (términos coherentes con la experiencia vivida por la población objetivo) y conceptual (conceptos traducidos deben ser explorados y eventos experimentados por la población peruana).$^{15} \mathrm{~A}$ partir de los análisis de los especialistas fueron realizadas las alteraciones sugeridas y elaborada la versión prefinal del instrumento SPAMP, versión en español (SPAMP-vE).

Con la versión prefinal del instrumento fue desarrollado el test, comprendiendo como quinta etapa del proceso de traducción. Esta etapa fue realizada con enfermeras del servicio de emergencia pediátrica del hospital Regional Lambayeque.

Así, se obtuvo la versión prefinal del instrumento, que fue sometida a la validación de contenido por otro comité de especialistas, el cual será llamado en este estudio por jueces de contenido. Los integrantes de este comité fueron seleccionados por medio de busqueda en el Directorio de registro de Investigadores e innovadores.

Se siguieron las recomendaciones de autor ${ }^{16}$ quien sugiere que los jueces deben ser en número de seis a veinte sujetos, para ello se eligió un número impar de especialistas, ya que esta condición evita el empate de opiniones y, con ello, permite la decisión mayoritaria. Entonces, se utilizará un número de al menos siete especialistas, lo que corresponde a $100 \%$ más 1 además de la recomendación según autor. ${ }^{16}$

La selección de los jueces se llevó a cabo en febrero del 2018, mediante muestreo intencional, el cual, el investigador selecciona intencionalmente sujetos que conocen los atributos del instrumento de investigación.

Para componer la muestra, los jueces necesitarían tener un doctorado en Enfermería y obtener una puntuación igual o superior a cinco, según el sistema de clasificación descrito por autora del instrumento en portugués.

La validación de contenido fue realizado con los siete jueces, habiendo sido adoptados como critérios para selección: tener experiencia clínica en la administración de medicamentos en la atención hospitalaria infantil y/o tener conocimiento o haber realizado investigación sobre validación de instrumentos de medida. Todos fueron doctores y docentes de educación superior, con media de ocho años en la asistencia al niño portador de condición crónica, siendo siete enfermeras.

\section{Participantes}

Las enfermeras del servicio de emergencia pediátrica del hospital Regional Lambayeque que participaron del test fueron orientadas individualmente a responder al instrumento conforme su vivencia diaria en la asistencia de enfermería al niño hospitalizado. Los instrumentos fueron entregados a las enfermeras y solicitado su devolución en su turno siguiente. Después de autocompletado, cada enfermero relato sus impresiones sobre él y sus respuestas para cada ítem.

Para la validación de contenido fueron entregados a los jueces el instrumento SPAMP-vE y un instrumento para validación abordando los ítems de clareza, pertinencia práctica y pertinencia teórica. ${ }^{16}$

\section{Analísis}

La validación de contenido de la versión español fue realizada por medio de la validación de las propiedades psicométricas, considerando o Coeficiente da validad de contenido (CVC), que corresponde al grado en que el instrumento es válido en relación con su contenido, ${ }^{14}$ utilizándose, por tanto, las notas de los jueces de 1 (pésimo) a 5 (excelente) en la escala de Likert para cada aspecto evaluado, para el cálculo fue realizado de la siguiente manera:

1) Con base en las notas de los jueces, se calculó el promedio de las notas de cada ítem $(\mathrm{Mx})$ :

$M x=\frac{\sum_{l=I}^{j} x}{j} 1$

Dónde $\Sigma x_{1}$ representa la suma de las notas de los jueces y $J$ representa el número de jueces que evaluaran cada ítem

2) Con base en el promedio, se calculó el coeficiente de validez de contenido de cada ítem $\left(\mathrm{CVC}_{\mathrm{i}}\right)$;

$C V C_{i=} \frac{M x}{V \operatorname{máx}}$

Donde $\mathrm{V}_{\text {máx }}$ representa el valor máximo que el ítem pudiera recibir

3) Se realizó el cálculo del error $\left(P_{e j}\right)$, para descontar posibles sesgos de los jueces evaluadores, para cada ítem:

Pei. $=\left(\frac{x}{j}\right) j$

4) Con eso, el coeficiente de validez de contenido final de cada ítem $\left(\mathrm{CVC}_{\mathrm{c}}\right.$ ) fue así calculado:

$C V C_{c}=C V C_{i--} P_{e i}$

5) Para el cálculo de CVC total del instrumento ( $\left.C V C_{t}\right)$, para cada una de las características (Pertinencia Práctica; Clareza de Lenguaje y Relevancia teórica) se utilizó:

$\mathrm{CVC}_{t}=\mathrm{Mcvc}_{i}-\mathrm{Mpe}_{i}$

Donde. $\mathrm{Mcvc}_{\text {, }}$ representa el promedio de los coeficientes de Validez de contenido de los ítems del instrumento y Mpe el promedio de los errores de los ítems del instrumento. El CVC se refiere al valor calculado para el instrumento en general. Esto es el promedio calculado para todos los ítems referente a la Pertinencia Práctica; Clareza de Lenguaje y Relevancia teórica

Se resalta que, apesar de la recomendación de ser consideradas aceptables apenas las preguntas que obtuviesen un CVC mayor que 0,8 , se opto por la no retirada de los ítems 
del instrumento para que se proceda con la evaluación de la confiabilidad, en el caso de la homogeneidad fue verificada por medio de la consistencia interna medida por el Alfa de Cronbach. El coeficiente mide el grado de covarianza de los ítems entre si, sirviendo como indicador de la consistencia interna del propio pre test y varia de 0 a 1 , en el que cero indica la ausencia total de consistencia interna de los items; y 1 la consistencia de $100 \%$. Los valores de alfa aceptables están entre 0,70 e 0,90, mostrando que hubo confiabilidad de las medidas. ${ }^{15}$

\section{Consideraciones éticas}

El estudio fue iniciado después de la aprobación por la Comisión de Ética del Hospital Regional de Lambayeque, Perú.
La autora del referido instrumento autorizo la realización de este proceso de traducción, adaptación transcultural y validación para el español en la realidad cultural del Perú. Fue solicitado el consentimiento informado a los participantes asegurando su anonimato.

\section{RESULTADOS}

El Cuadro 1 identifica los ítems del instrumento SPAMP en la versión en portugués y su versión final en español (SPAMP-vE), después de la traducción y validación del instrumento por los especialistas, bien como después del análisis de las propiedades psicométricas por los jueces de contenido.

Cuadro 1. Evaluación de la equivalencia entre el instrumento original en el idioma portugués y la versión traducida para el español. Lambayeque Perú, 2018.

\begin{tabular}{|c|c|c|c|}
\hline \multicolumn{4}{|c|}{ Ítems de respuesta del instrumento SPAMP en portugués } \\
\hline \multicolumn{3}{|c|}{ 1- Nunca } & 1- Nunca \\
\hline \multicolumn{3}{|c|}{ 2- Casi nunca } & 2- Casi nunca \\
\hline \multicolumn{3}{|c|}{ 3- A veces } & 3- $A$ veces \\
\hline \multicolumn{3}{|c|}{ 4- Casi siempre } & 4- Casi siempre \\
\hline \multicolumn{3}{|c|}{ 5- Siempre } & 5- Siempre \\
\hline & $\begin{array}{c}\text { Ítems del instrumento SPAMP en } \\
\text { portugués }\end{array}$ & $\begin{array}{c}\text { Ítems de la versión prefinal del } \\
\text { instrumento SPAMP en español, } \\
\text { después de la evaluación de la } \\
\text { equivalencia }\end{array}$ & $\begin{array}{l}\text { Acción e Ítems de la versión final } \\
\text { del instrumento SPAMP en español, } \\
\text { después de la validación de } \\
\text { contenido y confiabilidad }\end{array}$ \\
\hline 1. & $\begin{array}{l}\text { Utiliza no mínimo dois } \\
\text { identificadores (nome completo, } \\
\text { data de nascimento ou número } \\
\text { do prontuário) para confirmar } \\
\text { o paciente antes de administrar } \\
\text { medicamentos. }\end{array}$ & $\begin{array}{l}\text { Utiliza al menos dos identificadores } \\
\text { (nombre completo del paciente, } \\
\text { fecha de nacimiento o número } \\
\text { de expediente) para identificar } \\
\text { al paciente antes de administrar } \\
\text { medicamentos. }\end{array}$ & $\begin{array}{l}\text { ALTERADO: Utiliza al menos dos } \\
\text { identificadores (nombre completo } \\
\text { del niño, fecha de nacimiento } \\
\text { o número de historia clínica) } \\
\text { para identificar al niño antes de } \\
\text { administrar el medicamento. }\end{array}$ \\
\hline 2 & $\begin{array}{l}\text { Confere o nome do medicamento } \\
\text { com a prescrição antes de } \\
\text { administrá-lo ao paciente. }\end{array}$ & $\begin{array}{l}\text { Confiere el nombre del } \\
\text { medicamento con la prescripción } \\
\text { antes de administrarlo al paciente. }\end{array}$ & $\begin{array}{l}\text { ALTERADO: Confirma el nombre del } \\
\text { medicamento con la prescripción } \\
\text { médica antes de administrarlo al } \\
\text { niño. }\end{array}$ \\
\hline 3 & $\begin{array}{l}\text { Leva ao leito apenas os } \\
\text { medicamentos prescritos a um } \\
\text { único paciente. }\end{array}$ & $\begin{array}{l}\text { Lleva a la cama apenas los } \\
\text { medicamentos prescritos a un único } \\
\text { paciente. }\end{array}$ & $\begin{array}{l}\text { ALTERADO: Lleva a la cama sólo los } \\
\text { medicamentos prescritos a un único } \\
\text { niño. }\end{array}$ \\
\hline 4 & $\begin{array}{l}\text { Administra o medicamento por } \\
\text { ordem verbal somente em caso de } \\
\text { emergência. }\end{array}$ & $\begin{array}{l}\text { Administra el medicamento por } \\
\text { orden verbal solamente en caso de } \\
\text { emergencia. }\end{array}$ & MANTENIDO \\
\hline 5 & $\begin{array}{l}\text { Confere se o paciente não é alérgico } \\
\text { ao medicamento prescrito. }\end{array}$ & $\begin{array}{l}\text { Confiere si el paciente no es alérgico } \\
\text { al medicamento prescrito. }\end{array}$ & $\begin{array}{l}\text { ALTERADO: Confirma si el niño } \\
\text { no es alérgico al medicamento } \\
\text { prescrito, identificándolo de forma } \\
\text { diferenciada con pulsera y aviso en } \\
\text { la historia clínica, alertando a todo } \\
\text { el equipo. }\end{array}$ \\
\hline
\end{tabular}


Cuadro 1. Continuación...

\begin{tabular}{|c|c|c|c|}
\hline & $\begin{array}{c}\text { Ítems del instrumento SPAMP en } \\
\text { portugués }\end{array}$ & $\begin{array}{c}\text { Ítems de la versión prefinal del } \\
\text { instrumento SPAMP en español, } \\
\text { después de la evaluación de la } \\
\text { equivalencia }\end{array}$ & $\begin{array}{l}\text { Acción e Ítems de la versión final } \\
\text { del instrumento SPAMP en español, } \\
\text { después de la validación de } \\
\text { contenido y confiabilidad }\end{array}$ \\
\hline 6 & $\begin{array}{l}\text { Identifica o paciente alérgico de } \\
\text { forma diferenciada com pulseira e } \\
\text { aviso em prontuário, alertando toda } \\
\text { a equipe. }\end{array}$ & $\begin{array}{l}\text { Identifica el paciente alérgico de } \\
\text { forma diferenciada con pulsera y } \\
\text { aviso en la ficha médica, alertando a } \\
\text { todo el equipo. }\end{array}$ & AGRUPADO con ítem 5 \\
\hline 7 & $\begin{array}{l}\text { Identifica a via de administração } \\
\text { prescrita para o medicamento. }\end{array}$ & $\begin{array}{l}\text { Identifica la vía de administración } \\
\text { prescrita para el medicamento. }\end{array}$ & MANTENIDO \\
\hline 8 & $\begin{array}{l}\text { Verifica se a via prescrita é a } \\
\text { tecnicamente recomendada para } \\
\text { administrar o medicamento. }\end{array}$ & $\begin{array}{l}\text { Verifica si la vía prescrita es } \\
\text { la técnica recomendada para } \\
\text { administrar el medicamento. }\end{array}$ & MANTENIDO \\
\hline 9 & $\begin{array}{l}\text { Lava as mãos antes do preparo e } \\
\text { administração de medicamentos. }\end{array}$ & $\begin{array}{l}\text { Lava las manos antes de la } \\
\text { preparación y administración de } \\
\text { medicamentos. }\end{array}$ & MANTENIDO. \\
\hline 10 & $\begin{array}{l}\text { Utiliza materiais e técnicas } \\
\text { assépticas para administrar } \\
\text { medicamentos por via intravenosa } \\
\text { e para outras vias que exijam esse } \\
\text { tipo de técnica. }\end{array}$ & $\begin{array}{l}\text { Utiliza materiales y técnicas } \\
\text { asépticas para administrar } \\
\text { medicamentos por vía intravenosa } \\
\text { y para otras vías que exijan ese tipo } \\
\text { de técnica. }\end{array}$ & $\begin{array}{l}\text { ALTERADO: Utiliza materiales y } \\
\text { técnicas asépticas para administrar } \\
\text { medicamentos según las diferentes } \\
\text { vías de administración. }\end{array}$ \\
\hline 11 & $\begin{array}{l}\text { Prepara o medicamento } \\
\text { imediatamente antes da sua } \\
\text { administração. }\end{array}$ & $\begin{array}{l}\text { Prepara el medicamento } \\
\text { inmediatamente antes de su } \\
\text { administración }\end{array}$ & MANTENIDO \\
\hline 12 & $\begin{array}{l}\text { Administra o medicamento na hora } \\
\text { certa. }\end{array}$ & $\begin{array}{l}\text { Administra el medicamento en la } \\
\text { hora correcta. }\end{array}$ & MANTENIDO \\
\hline 13 & $\begin{array}{l}\text { Adéqua os horários de } \\
\text { administração dos medicamentos à } \\
\text { rotina de uso já estabelecida antes } \\
\text { da internação. }\end{array}$ & $\begin{array}{l}\text { Adecua los horarios de } \\
\text { administración de los medicamentos } \\
\text { a la rutina ya establecida antes de } \\
\text { su hospitalización }\end{array}$ & MANTENIDO \\
\hline 14 & $\begin{array}{l}\text { Confere atentamente a dose } \\
\text { prescrita para o medicamento. }\end{array}$ & $\begin{array}{l}\text { Confiere atentamente la dosis } \\
\text { prescrita para el medicamento. }\end{array}$ & $\begin{array}{l}\text { ALTERADO: Confirma atentamente } \\
\text { la dosis según la prescripción } \\
\text { médica para el medicamento. }\end{array}$ \\
\hline 15 & $\begin{array}{l}\text { Confere a velocidade de } \\
\text { gotejamento, a programação e } \\
\text { o funcionamento de bombas de } \\
\text { infusão contínua com a prescrição. }\end{array}$ & $\begin{array}{l}\text { Confiere la velocidad del goteo, la } \\
\text { programación y el funcionamiento } \\
\text { de bombas de infusión continúa con } \\
\text { la prescripción. }\end{array}$ & $\begin{array}{l}\text { ALTERADO: Confirma la velocidad } \\
\text { del goteo, la programación y } \\
\text { funcionamiento de bombas de } \\
\text { infusión continúa con la prescripción } \\
\text { médica. }\end{array}$ \\
\hline 16 & $\begin{array}{l}\text { Realiza dupla checagem dos cálculos } \\
\text { para preparo e para administração } \\
\text { de medicamentos potencialmente } \\
\text { perigosos ou de alta vigilância. }\end{array}$ & $\begin{array}{l}\text { Realiza doble chequeo de los } \\
\text { cálculos para preparación y } \\
\text { administración de medicamentos } \\
\text { potencialmente peligrosos o } \\
\text { medicamentos de alta vigilancia }\end{array}$ & $\begin{array}{l}\text { ALTERADO: Realiza doble chequeo, } \\
\text { por dos profesionales, los cálculos } \\
\text { de dilución y administración de } \\
\text { medicamentos potencialmente } \\
\text { peligrosos o medicamentos de alta } \\
\text { vigilancia. }\end{array}$ \\
\hline 17 & $\begin{array}{l}\text { Utiliza instrumentos de } \\
\text { medida padrão no preparo } \\
\text { de medicamentos para medir } \\
\text { doses com exatidão (ex: seringas } \\
\text { milimetradas). }\end{array}$ & $\begin{array}{l}\text { Utiliza instrumentos de medida } \\
\text { estándar en la preparación de } \\
\text { medicamentos para medir la dosis } \\
\text { exacta (ej: jeringas milimetradas). }\end{array}$ & $\begin{array}{l}\text { ALTERADO: Utiliza instrumentos de } \\
\text { medida estándar en la preparación } \\
\text { de medicamentos para medir } \\
\text { la dosis exacta (ejm: jeringas } \\
\text { milimetradas, vasos dosificados). }\end{array}$ \\
\hline
\end{tabular}


Cuadro 1. Continuación...

\begin{tabular}{|c|c|c|c|}
\hline & $\begin{array}{c}\text { Ítems del instrumento SPAMP en } \\
\text { portugués }\end{array}$ & $\begin{array}{c}\text { Ítems de la versión prefinal del } \\
\text { instrumento SPAMP en español, } \\
\text { después de la evaluación de la } \\
\text { equivalencia }\end{array}$ & $\begin{array}{l}\text { Acción e Ítems de la versión final } \\
\text { del instrumento SPAMP en español, } \\
\text { después de la validación de } \\
\text { contenido y confiabilidad }\end{array}$ \\
\hline 18 & $\begin{array}{l}\text { Devolve à farmácia as sobras de } \\
\text { medicamentos não administrados. }\end{array}$ & $\begin{array}{l}\text { Devuelve a la farmacia las sobras de } \\
\text { medicamentos no administrados. }\end{array}$ & MANTENIDO \\
\hline 19 & $\begin{array}{l}\text { Registra na prescrição o horário da } \\
\text { administração do medicamento } \\
\text { imediatamente após cada dose. }\end{array}$ & $\begin{array}{l}\text { Registra en la prescripción el } \\
\text { horario de la administración del } \\
\text { medicamento inmediatamente } \\
\text { después de cada dosis. }\end{array}$ & $\begin{array}{l}\text { ALTERADO: Registra en el Kárdex } \\
\text { el horario de la administración y } \\
\text { en la Historia clínica ocurrencias } \\
\text { del medicamento inmediatamente } \\
\text { después de administrar cada dosis. }\end{array}$ \\
\hline 20 & $\begin{array}{l}\text { Registra em prontuário todas } \\
\text { as ocorrências relacionadas aos } \\
\text { medicamentos (ex: adiamentos, } \\
\text { cancelamentos, desabastecimento, } \\
\text { recusa do paciente e eventos } \\
\text { adversos). }\end{array}$ & $\begin{array}{l}\text { Registra en la ficha de registro todas } \\
\text { las ocurrencias relacionadas a los } \\
\text { medicamentos (ejm: aplazamientos, } \\
\text { cancelaciones, desabastecimiento, } \\
\text { rechazo o negativa del paciente y } \\
\text { eventos adversos). }\end{array}$ & AGRUPADO con ítem 19. \\
\hline 21 & $\begin{array}{l}\text { Registra em prontuário e notifica à } \\
\text { Gerência de Riscos e/ou Núcleo de } \\
\text { Segurança do Paciente os eventuais } \\
\text { incidentes relacionados à terapia } \\
\text { medicamentosa. }\end{array}$ & $\begin{array}{l}\text { Registra en la ficha médica y notifica } \\
\text { a la gerencia de riesgos y/o Núcleo } \\
\text { de seguridad del paciente los } \\
\text { eventuales incidentes relacionados } \\
\text { con la terapia medicamentosa. }\end{array}$ & $\begin{array}{l}\text { ALTERADO: Notifica en la Ficha de } \\
\text { Registro y reporte de incidentes, } \\
\text { reacciones adversas y eventos } \\
\text { adversos a la oficina de Gestión de } \\
\text { Calidad. }\end{array}$ \\
\hline 22 & $\begin{array}{l}\text { Mantém registro adequado } \\
\text { de medicamentos preparados } \\
\text { que serão armazenados (com } \\
\text { data e horário da manipulação, } \\
\text { concentração do medicamento, } \\
\text { nome do responsável pelo preparo } \\
\text { e validade) }\end{array}$ & $\begin{array}{l}\text { Mantiene registro adecuado de } \\
\text { medicamentos preparados que } \\
\text { serán almacenados (con fecha } \\
\text { y horario de la manipulación, } \\
\text { concentración del medicamento, } \\
\text { nombre del responsable de la } \\
\text { preparación y la validez). }\end{array}$ & MANTENIDO \\
\hline 23 & $\begin{array}{l}\text { Monitora a temperatura da } \\
\text { geladeira de acondicionamento } \\
\text { de medicamentos, registrando } \\
\text { os valores máximo e mínimo } \\
\text { diariamente. }\end{array}$ & $\begin{array}{l}\text { Monitorea la temperatura de la } \\
\text { refrigeradora de acondicionamiento } \\
\text { de medicamentos registrando } \\
\text { los valores máximo y mínimo } \\
\text { diariamente. }\end{array}$ & $\begin{array}{l}\text { ALTERADO: Monitorea la } \\
\text { temperatura de la refrigeradora } \\
\text { de acondicionamiento de los } \\
\text { medicamentos registrando los } \\
\text { valores diariamente. }\end{array}$ \\
\hline 24 & $\begin{array}{l}\text { Esclarece dúvidas sobre a prescrição } \\
\text { junto ao prescritor antes de } \\
\text { administrar o medicamento (ex: } \\
\text { inelegibilidade da prescrição, } \\
\text { indicação do medicamento, } \\
\text { posologia, "fazer se necessário", } \\
\text { "a critério médico", unidade } \\
\text { de medidas utilizadas, forma } \\
\text { farmacêutica, via de administração } \\
\text { e dose). }\end{array}$ & $\begin{array}{l}\text { Aclara dudas sobre la prescripción } \\
\text { junto al prescriptor antes de } \\
\text { administrar el medicamento (ejm: } \\
\text { inelegibilidad de la prescripción, } \\
\text { indicación del medicamento, } \\
\text { posología, "si es necesario", "a } \\
\text { criterio médico, Unidad de medidas } \\
\text { utilizadas, forma farmacéutica, vía } \\
\text { de administración y dosis) }\end{array}$ & $\begin{array}{l}\text { ALTERADO: Aclara dudas sobre } \\
\text { inelegibilidad de la prescripción, } \\
\text { indicación del medicamento y } \\
\text { posología antes de administrar el } \\
\text { medicamento. }\end{array}$ \\
\hline 25 & $\begin{array}{l}\text { Orienta o paciente e o } \\
\text { acompanhante sobre o medicamento } \\
\text { administrado (nome), aspecto } \\
\text { (cor e formato) justificativa da } \\
\text { indicação, frequência com que será } \\
\text { administrado e efeitos esperados. }\end{array}$ & $\begin{array}{l}\text { Orienta al paciente y al acompañante } \\
\text { sobre el medicamento administrado } \\
\text { (nombre) aspecto (color y forma) } \\
\text { justificación de la indicación, } \\
\text { la frecuencia con la que será } \\
\text { administrado y los efectos esperados. }\end{array}$ & $\begin{array}{l}\text { ALTERADO: Orienta al niño y al } \\
\text { acompañante sobre el medicamento } \\
\text { administrado y la justificación de } \\
\text { la indicación, la frecuencia con la } \\
\text { que será administrado y los efectos } \\
\text { esperados. }\end{array}$ \\
\hline
\end{tabular}


Cuadro 1. Continuación...

\begin{tabular}{|c|c|c|c|}
\hline & $\begin{array}{l}\text { Ítems del instrumento SPAMP en } \\
\text { portugués }\end{array}$ & $\begin{array}{c}\text { Ítems de la versión prefinal del } \\
\text { instrumento SPAMP en español, } \\
\text { después de la evaluación de la } \\
\text { equivalencia }\end{array}$ & $\begin{array}{c}\text { Acción e Ítems de la versión final } \\
\text { del instrumento SPAMP en español, } \\
\text { después de la validación de } \\
\text { contenido y confiabilidad }\end{array}$ \\
\hline 26 & $\begin{array}{l}\text { Checa se o medicamento a } \\
\text { ser administrado possui forma } \\
\text { farmacêutica (ex: ampola, frasco, } \\
\text { comprimido) compatível com a via } \\
\text { de administração prescrita. }\end{array}$ & $\begin{array}{l}\text { Verifica si el medicamento a ser } \\
\text { administrado posee la forma } \\
\text { farmacéutica (ejm: ampolla, frasco, } \\
\text { comprimido) compatible con la vía } \\
\text { de administración prescrita. }\end{array}$ & $\begin{array}{l}\text { ALTERADO: Verifica si el } \\
\text { medicamento a ser administrado } \\
\text { posee la presentación farmacéutica } \\
\text { compatible con la vía de } \\
\text { administración de la prescripción } \\
\text { médica. }\end{array}$ \\
\hline 27 & $\begin{array}{l}\text { Avalia o paciente para identificar, } \\
\text { quando possível, se o medicamento } \\
\text { teve o efeito desejado. }\end{array}$ & $\begin{array}{l}\text { Evalúa al paciente para } \\
\text { identificar, cuando sea posible, } \\
\text { si el medicamento tuvo el efecto } \\
\text { deseado. }\end{array}$ & $\begin{array}{l}\text { ALTERADO: Evalúa al niño para } \\
\text { identificar cuando sea posible, si } \\
\text { el medicamento tuvo el efecto } \\
\text { deseado. }\end{array}$ \\
\hline 28 & $\begin{array}{l}\text { Informa ao prescritor todos os } \\
\text { efeitos diferentes do esperado } \\
\text { (em intensidade e forma) para o } \\
\text { medicamento. }\end{array}$ & $\begin{array}{l}\text { Informa al prescriptor todos los } \\
\text { efectos diferentes de lo esperado } \\
\text { (en intensidad y forma) para el } \\
\text { medicamento. }\end{array}$ & $\begin{array}{l}\text { ALTERADO: Informa al médico } \\
\text { que prescribió todos los efectos } \\
\text { diferentes de lo esperado (en } \\
\text { intensidad y forma) para el } \\
\text { medicamento. }\end{array}$ \\
\hline
\end{tabular}

De acuerdo con la evaluación expuesta en el Cuadro 1, nueve ítems fueron mantenidos sin alteraciones y diecisiete en su contenido tuvieron modificaciones. Se resalta que fueron agrupados; el ítem 6 con el 5 y el ítem 20 con el 19, pues los jueces consideraron que las acciones complementarias, correspondían a un único ítem. Así, la versión final quedo constituida por 26 ítems.

En el test, la versión prefinal del instrumento SPAMP-vE fue aplicada a tres enfermeras, de sexo femenino, siendo dos con 30 años y una con 41 años de edad, con más de cinco años en la asistencia de enfermería en la unidad hospitalaria, siendo cada una en unidad diferente: Unidad de Terapia intensiva Pediatrica (UTIP), emergencia y hospitalización. El tiempo médio utilizado para auto completar el instrumento SPAMPvE fue de 10 minutos. La evaluación de los elementos de la versión prefinal del instrumento SPAMP en idioma español por los enfermeros muestra que los ítems eran comprensibles, con opciones de respuestas claras y fácilmente elegibles, sin necesidad de modificaciones.

Concluidas todas las etapas del proceso de traducción y adaptación transcultural del instrumento, se obtuvo la versión prefinal del instrumento SPAMP-vE, siendo realizado el análisis de las propiedades psicométricas de validad (contenido-CVC); y de confiabilidad (homogeneidad: Alfa de Cronbach).

Se observa en la Tabla 1 que la mayoría de los 26 ítems evaluados obtuvo $\mathrm{CVC}_{\mathrm{c}}>0,80$ (punto de corte), excepto: cuatro ítems en la pertinencia práctica, siete ítems en la clareza de lenguaje y un ítem en la relevancia teórica.

Los critérios de pertinencia práctica, clareza del lenguaje y relevancia teórica presentaron, respectivamente, un $\mathrm{CVC}_{\mathrm{t}}$ de 0,$97 ; 0,97$ y 0,96 . Como el $\mathrm{CVC}_{\mathrm{t}}$ de los tres critérios de la escala (PP, CL, RT) fueron aceptables, se opto por mantener los enunciados y la máxima proximidad con la escala original.

El comité de jueces permitió un análisis de las estructuras de cada ítem, cuyas contribuciones y alteraciones sugeridas en el proceso de validación posibilitaron el perfeccionamiento de los ítems. De esa forma, las justificativas para mantener, alterar, agrupar y/o excluir los ítems, conforme sugerencias de los jueces, pueden ser observados en el Cuadro 1.

La confiabilidad del instrumento con sus 26 ítems fue evaluada por medio de la consistencia interna, medida por el cálculo del coeficiente alfa de Cronbach que fue de 0,921.

A partir de la evaluación de los jueces, fue calculado el Alfa de Cronbach relacionado a la pertinencia práctica $(0,91)$, a la clareza del lenguaje $(0,91)$ y a la relevancia $(0,91)$, lo que denota consistencia interna adecuada. ${ }^{14} \mathrm{Si}$ algún ítem fuera excluído, el alfa permanecería 0,91 , lo que sugiere alta confiabilidad y fidedignidad del instrumento para observar seguridad del paciente en la administración de medicamentos en pediatría (Tabla 1).

Esa etapa posibilita la elaboración de la segunda versión del instrumento de seguridad del paciente en la administración de medicamentos en pediatría (SPAMP-vE), (Cuadro 1). Después se obtuvo la versión final del instrumento SPAMP-vE, el mismo que fue enviado para la autora ${ }^{16}$ que emitio opinión favorable, concordando con la traducción y las alteraciones realizadas en el instrumento SPAMP, visto que la versión en español presenta el mismo contenido y sentido de la versión original, ratificando la adaptación transcultural del instrumento SPAMP en la versión español para uso en el Perú.

A continuacion se presenta el Cuadro 2 del instrumento en su version final en español. 
Tabla 1. Distribución del Coeficiente de validad de contenido para cada ítem $\left(\mathrm{CVC}_{c}\right)$ y los índices del Alfa de Cronbach de ítem total de acuerdo con el análisis de los jueces. Lambayeque, Perú, 2018.

\begin{tabular}{|c|c|c|c|c|c|c|}
\hline \multicolumn{3}{|c|}{ CVCc* } & \multirow{2}{*}{ Ítem } & \multirow{2}{*}{\multicolumn{3}{|c|}{$\begin{array}{l}\text { Estadísticas de ítem-total Alfa de } \\
\text { Cronbach si el ítem fuera excluído }\end{array}$}} \\
\hline $\mathrm{PP}^{+}$ & $\mathrm{CL}^{\ddagger}$ & $\mathrm{R}^{\text {? }}$ & & & & \\
\hline 1 & 1 & 1 & $\begin{array}{l}\text { 1. Utiliza al menos dos identificadores (nombre completo del } \\
\text { niño, fecha de nacimiento o número de historia clínica) para } \\
\text { identificar al niño antes de administrar el medicamento. }\end{array}$ & 0,921 & 0,921 & 0,920 \\
\hline 0,71 & 0,71 & 0,80 & $\begin{array}{l}\text { 2. Confirma el nombre del medicamento con la } \\
\text { prescripción médica antes de administrarlo al niño }\end{array}$ & 0,919 & 0,919 & 0,919 \\
\hline 0,94 & 0,91 & 0,97 & $\begin{array}{l}\text { 3. Lleva a la cama sólo los medicamentos prescritos a un } \\
\text { único niño. }\end{array}$ & 0,920 & 0,919 & 0,920 \\
\hline 0,63 & 0,74 & 0,91 & $\begin{array}{l}\text { 4. Administra el medicamento por orden verbal } \\
\text { solamente en caso de emergencia. }\end{array}$ & 0,919 & 0,918 & 0,918 \\
\hline 0,83 & 0,66 & 0,92 & $\begin{array}{l}\text { 5. Confirma si el niño no es alérgico al medicamento } \\
\text { prescrito, identificándolo de forma diferenciada con pulsera } \\
\text { y aviso en la historia clínica, alertando a todo el equipo. }\end{array}$ & 0,919 & 0,919 & 0,920 \\
\hline 0,97 & 0,89 & 0,97 & $\begin{array}{l}\text { 6. Identifica la vía de administración prescrita para el } \\
\text { medicamento. }\end{array}$ & 0,920 & 0,920 & 0,920 \\
\hline 0,97 & 0,97 & 0,94 & $\begin{array}{l}\text { 7. Verifica si la vía prescrita es la técnica recomendada } \\
\text { para administrar el medicamento. }\end{array}$ & 0,920 & 0,920 & 0,920 \\
\hline 0,83 & 0,83 & 0,83 & $\begin{array}{l}\text { 8. Lava las manos antes de la preparación y } \\
\text { administración de medicamentos. }\end{array}$ & 0,920 & 0,920 & 0,919 \\
\hline 1 & 1 & 1 & $\begin{array}{l}\text { 9. Utiliza materiales y técnicas asépticas para administrar } \\
\text { medicamentos según las diferentes vías de administración. }\end{array}$ & 0,919 & 0,919 & 0,919 \\
\hline 1 & 1 & 1 & $\begin{array}{l}\text { 10. Prepara el medicamento inmediatamente antes de su } \\
\text { administración. }\end{array}$ & 0,921 & 0,921 & 0,921 \\
\hline 0,89 & 0,89 & 0,89 & 11. Administra el medicamento en la hora correcta. & 0,921 & 0,921 & 0,921 \\
\hline 0,80 & 0,77 & 0,83 & $\begin{array}{l}\text { 12. Adecua los horarios de administración de los } \\
\text { medicamentos a la rutina ya establecida antes de su } \\
\text { hospitalización. }\end{array}$ & 0,920 & 0,920 & 0,920 \\
\hline 0,71 & 0,71 & 0,69 & $\begin{array}{l}\text { 13. Confirma atentamente la dosis según la prescripción } \\
\text { médica para el medicamento. }\end{array}$ & 0,919 & 0,919 & 0,919 \\
\hline 0,77 & 0,74 & 0,89 & $\begin{array}{l}\text { 14. Confirma la velocidad del goteo, la programación y } \\
\text { funcionamiento de bombas de infusión continua con la } \\
\text { prescripción médica. }\end{array}$ & 0,919 & 0,919 & 0,920 \\
\hline 0,97 & 0,94 & 0,94 & $\begin{array}{l}\text { 15. Realiza doble chequeo, por dos profesionales, de los } \\
\text { cálculos de dilución y administración de medicamentos } \\
\text { potencialmente peligrosos o medicamentos de alta vigilancia. }\end{array}$ & 0,918 & 0,918 & 0,919 \\
\hline 0,94 & 0,91 & 0,94 & $\begin{array}{l}\text { 16. Utiliza instrumentos de medida estándar en la } \\
\text { preparación de medicamentos para medir la dosis exacta } \\
\text { (ejm: jeringas milimetradas, vasos dosificados). }\end{array}$ & 0,920 & 0,920 & 0,920 \\
\hline 0,89 & 0,84 & 0,91 & $\begin{array}{l}\text { 17. Devuelve a la farmacia las sobras de medicamentos } \\
\text { no administrados. }\end{array}$ & 0,920 & 0,919 & 0,920 \\
\hline 0,89 & 0,84 & 0,9 & $\begin{array}{l}\text { 18. Registra en el Kárdex el horario de la administración } \\
\text { y en la Historia clínica ocurrencias del medicamento } \\
\text { inmediatamente después de administrar cada dosis. }\end{array}$ & 0,920 & 0,920 & 0,919 \\
\hline
\end{tabular}

Nota: ${ }^{*}$ CVC : Coeficiente de Validad de Contenido para cada ítem; ${ }^{\dagger}$ PP: Pertinencia Practica; ${ }^{\ddagger} \mathrm{CL}$ : Clareza de Lenguaje; ${ }^{2}$; Relevancia;?? $\mathrm{CVC}$ : Coeficiente de Validad de Contenido total de la característica. Fuente: Datos de la investigación. 
Tabla 1. Continuación...

\begin{tabular}{|c|c|c|c|c|c|c|}
\hline \multicolumn{3}{|c|}{ CVCc* } & \multirow{2}{*}{ Ítem } & \multirow{2}{*}{\multicolumn{3}{|c|}{$\begin{array}{l}\text { Estadísticas de ítem-total Alfa de } \\
\text { Cronbach si el ítem fuera excluído }\end{array}$}} \\
\hline $\mathrm{PP}^{+}$ & $\mathrm{CL}^{\ddagger}$ & $\mathrm{R}^{?}$ & & & & \\
\hline 0,89 & 0,86 & 0,91 & $\begin{array}{l}\text { 19. Notifica en la Ficha de Registro y reporte de } \\
\text { incidentes, reacciones adversas y eventos adversos a la } \\
\text { oficina de Gestión de Calidad. }\end{array}$ & 0,919 & 0,920 & 0,921 \\
\hline 0,91 & 0,97 & 1 & $\begin{array}{l}\text { 20. Mantiene registro adecuado de medicamentos } \\
\text { preparados que serán almacenados (con fecha y horario } \\
\text { de la manipulación, concentración del medicamento, } \\
\text { nombre del responsable de la preparación y la validez). }\end{array}$ & 0,920 & 0,919 & 0,921 \\
\hline 0,94 & 0,91 & 1 & $\begin{array}{l}\text { 21. Monitorea la temperatura de la refrigeradora de } \\
\text { acondicionamiento de los medicamentos registrando los } \\
\text { valores diariamente. }\end{array}$ & 0,920 & 0,919 & 0,920 \\
\hline 0,83 & 0,69 & 0,83 & $\begin{array}{l}\text { 22. Aclara dudas sobre inelegibilidad de la prescripción, } \\
\text { indicación del medicamento y posología antes de } \\
\text { administrar el medicamento. }\end{array}$ & 0,920 & 0,920 & 0,920 \\
\hline 0,91 & 0,89 & 0,89 & $\begin{array}{l}\text { 24. Verifica si el medicamento a ser administrado posee } \\
\text { la presentación farmacéutica compatible con la vía de } \\
\text { administración de la prescripción médica. }\end{array}$ & 0,921 & 0,921 & 0,921 \\
\hline 1 & 1 & 1 & $\begin{array}{l}\text { 25. Evalúa al niño para identificar cuando sea posible, si el } \\
\text { medicamento tuvo el efecto deseado. }\end{array}$ & 0,919 & 0,919 & 0,919 \\
\hline 0,89 & 0,89 & 0,89 & $\begin{array}{l}\text { 26. Informa al médico que prescribió todos los efectos diferentes } \\
\text { de lo esperado (en intensidad y forma) para el medicamento. }\end{array}$ & 0,921 & 0,921 & 0,921 \\
\hline
\end{tabular}

Nota: ${ }^{*} \mathrm{CVC}_{\mathrm{c}}$ : Coeficiente de Validad de Contenido para cada ítem; ${ }^{+P P}$ : Pertinencia Practica; ${ }^{\ddagger} \mathrm{CL}$ : Clareza de Lenguaje; ${ }^{\mathrm{R}}$; Relevancia;? $\mathrm{CV} \mathrm{C}_{\mathrm{t}}$ : Coeficiente de Validad de Contenido total de la característica. Fuente: Datos de la investigación.

Cuadro 2. Versión final traducida para el español del instrumento Seguridad del Paciente en la Administración de Medicamento (SPAM-vE). Lambayeque Perú, 2018.

\begin{tabular}{|c|c|c|c|c|c|c|}
\hline \multirow[t]{2}{*}{ Dominios } & \multirow[t]{2}{*}{ ADMINISTRACION DE MEDICAMENTOS } & Nunca & $\begin{array}{c}\text { Casi } \\
\text { Nunca }\end{array}$ & A veces & $\begin{array}{c}\text { Casi } \\
\text { Siempre }\end{array}$ & Siempre \\
\hline & & 1 & 2 & 3 & 4 & 5 \\
\hline $\begin{array}{l}\text { Paciente } \\
\text { Correcto }\end{array}$ & $\begin{array}{l}\text { 1. Utiliza al menos dos identificadores (nombre } \\
\text { completo del niño, fecha de nacimiento o número } \\
\text { de historia clínica) para identificar al niño antes de } \\
\text { administrar medicamento. }\end{array}$ & & & & & \\
\hline \multirow{4}{*}{$\begin{array}{l}\text { Medicamento } \\
\text { Correcto }\end{array}$} & $\begin{array}{l}\text { 2. Confirma el nombre del medicamento con la } \\
\text { prescripción médica antes de administrarlo al niño. }\end{array}$ & & & & & \\
\hline & $\begin{array}{l}\text { 3. Lleva a la cama sólo los medicamentos prescritos a } \\
\text { un único niño. }\end{array}$ & & & & & \\
\hline & $\begin{array}{l}\text { 4. Administra el medicamento por orden verbal } \\
\text { solamente en caso de emergencia. }\end{array}$ & & & & & \\
\hline & $\begin{array}{l}\text { 5. Confirma si el niño no es alérgico al medicamento } \\
\text { prescrito, identificándolo de forma diferenciada con pulsera } \\
\text { y aviso en la historia clínica, alertando a todo el equipo. }\end{array}$ & & & & & \\
\hline
\end{tabular}


Cuadro 2. Continuación...

\begin{tabular}{|c|c|c|c|c|c|c|}
\hline \multirow[t]{2}{*}{ Dominios } & \multirow[t]{2}{*}{ ADMINISTRACION DE MEDICAMENTOS } & Nunca & $\begin{array}{c}\text { Casi } \\
\text { Nunca }\end{array}$ & A veces & $\begin{array}{c}\text { Casi } \\
\text { Siempre }\end{array}$ & Siempre \\
\hline & & 1 & 2 & 3 & 4 & 5 \\
\hline \multirow{4}{*}{ Vía correcta } & $\begin{array}{l}\text { 6. Identifica la vía de administración prescrita para el } \\
\text { medicamento }\end{array}$ & & & & & \\
\hline & $\begin{array}{l}\text { 7.Verifica si la vía prescrita es la técnica recomendada } \\
\text { para administrar el medicamento }\end{array}$ & & & & & \\
\hline & $\begin{array}{l}\text { 8. Lava las manos antes de la preparación y } \\
\text { administración de medicamentos. }\end{array}$ & & & & & \\
\hline & $\begin{array}{l}\text { 9. Utiliza materiales y técnicas asépticas para } \\
\text { administrar medicamentos según las diferentes vías de } \\
\text { administración. }\end{array}$ & & & & & \\
\hline \multirow{3}{*}{ Hora correcta } & $\begin{array}{l}\text { 10. Prepara el medicamento inmediatamente antes de } \\
\text { su administración. }\end{array}$ & & & & & \\
\hline & 11. Administra el medicamento en la hora correcta. & & & & & \\
\hline & $\begin{array}{l}\text { 12. Adecua los horarios de administración de los } \\
\text { medicamentos a la rutina ya establecida antes de su } \\
\text { hospitalización. }\end{array}$ & & & & & \\
\hline \multirow{5}{*}{$\begin{array}{l}\text { Dosis } \\
\text { correcta }\end{array}$} & $\begin{array}{l}\text { 13. Confirma atentamente la dosis según la prescripción } \\
\text { médica para el medicamento. }\end{array}$ & & & & & \\
\hline & $\begin{array}{l}\text { 14. Confirma la velocidad del goteo, la programación y } \\
\text { funcionamiento de bombas de infusión continua con la } \\
\text { prescripción médica. }\end{array}$ & & & & & \\
\hline & $\begin{array}{l}\text { 15. Realiza doble chequeo por dos profesionales, de los } \\
\text { cálculos de dilución y administración de medicamentos } \\
\text { potencialmente peligrosos o medicamentos de alta } \\
\text { vigilancia. }\end{array}$ & & & & & \\
\hline & $\begin{array}{l}\text { 16. Utiliza instrumentos de medida estándar en la } \\
\text { preparación de medicamentos para medir la dosis } \\
\text { exacta (ej: jeringas milimetradas, vasos dosificados) }\end{array}$ & & & & & \\
\hline & $\begin{array}{l}\text { 17. Devuelve a la farmacia las sobras de medicamentos } \\
\text { no administrados. }\end{array}$ & & & & & \\
\hline \multirow{4}{*}{$\begin{array}{l}\text { Registro } \\
\text { correcto de la } \\
\text { administración }\end{array}$} & $\begin{array}{l}\text { 18. Registra en el Kárdex el horario de la administración } \\
\text { y en la historia clínica ocurrencias del medicamento } \\
\text { inmediatamente después de administrar cada dosis. }\end{array}$ & & & & & \\
\hline & $\begin{array}{l}\text { 19. Notifica en la Ficha de Registro y reporte de } \\
\text { incidentes, reacciones adversa y eventos adversos a la } \\
\text { oficina de Gestión de Calidad. }\end{array}$ & & & & & \\
\hline & $\begin{array}{l}\text { 20. Mantiene registro adecuado de medicamentos } \\
\text { preparados que serán almacenados (con fecha y horario } \\
\text { de la manipulación, concentración del medicamento, } \\
\text { nombre del responsable de la preparación y la validez). }\end{array}$ & & & & & \\
\hline & $\begin{array}{l}\text { 21. Monitorea la temperatura de la refrigeradora de } \\
\text { acondicionamiento de los medicamentos registrando } \\
\text { los valores diariamente. }\end{array}$ & & & & & \\
\hline
\end{tabular}


Cuadro 2. Continuación...

\begin{tabular}{|c|c|c|c|c|c|c|}
\hline \multirow[t]{2}{*}{ Dominios } & ADMINISTRACION DE MEDICAMENTOS & Nunca & $\begin{array}{c}\text { Casi } \\
\text { Nunca }\end{array}$ & A veces & $\begin{array}{c}\text { Casi } \\
\text { Siempre } \\
\end{array}$ & Siempre \\
\hline & & 1 & 2 & 3 & 4 & 5 \\
\hline \multirow{2}{*}{$\begin{array}{l}\text { Orientación } \\
\text { correcta }\end{array}$} & $\begin{array}{l}\text { 22. Aclara dudas sobre inelegibilidad de la prescripción, } \\
\text { indicación del medicamento y posología antes de } \\
\text { administrar el medicamento. }\end{array}$ & & & & & \\
\hline & $\begin{array}{l}\text { 23. Orienta al niño y al acompañante sobre el } \\
\text { medicamento administrado y la justificación, de la } \\
\text { indicación, la frecuencia con la que será administrado y } \\
\text { los efectos esperados. }\end{array}$ & & & & & \\
\hline $\begin{array}{l}\text { Forma } \\
\text { correcta }\end{array}$ & $\begin{array}{l}\text { 24. Verifica si el medicamento a ser administrado posee } \\
\text { la presentación farmacéutica compatible con la vía de } \\
\text { administración de la prescripción médica. }\end{array}$ & & & & & \\
\hline \multirow{2}{*}{$\begin{array}{l}\text { Respuesta } \\
\text { correcta }\end{array}$} & $\begin{array}{l}\text { 25. Evalúa al niño para identificar cuando sea posible, si } \\
\text { el medicamento tuvo el efecto deseado. }\end{array}$ & & & & & \\
\hline & $\begin{array}{l}\text { 26. Informa al médico que prescribió todos los efectos } \\
\text { diferentes de lo esperado (en intensidad y forma) para } \\
\text { el medicamento. }\end{array}$ & & & & & \\
\hline
\end{tabular}

\section{DISCUSIÓN}

La traducción y la adaptación de instrumentos previamente validados en otros países es un procedimiento legítimo que, además de reducir costos y facilitar el intercambio entre investigadores en el ámbito internacional, posibilita diálogos acerca de la seguridad del paciente en diversos aspectos, inclusive referentes a la seguridad en la administración de medicamentos.

La seguridad del paciente en pediatría es compleja e involucra acciones promovidas por las instituciones de salud para reducir a un mínimo aceptable el riesgo de hacer daño desnecesario asociado al cuidado de la salud. ${ }^{15}$

Dado este hecho, el procedimiento de traducción y adaptación cultural del instrumento de seguridad del paciente en la administración de medicamentos en pediatría (SPAMP), fue realizado de forma sistemática, de modo que los 28 ítems fueron adaptados en cuanto a las equivalencias semánticas, idiomática, experimental y conceptual por el comité de jueces. De ese modo, fue posible llegar a un instrumento con 26 ítems con más clareza y adecuación para ser utilizado en la etapa del test, con modificaciones que involucran ejemplificaciones y substituciones de términos y expresiones, cuyo objetivo principal fue facilitar la comprensión de los ítems del instrumento por los sujetos de estudio y así asegurar la equivalencia transcultural. ${ }^{16}$

Se enfatiza que los estudios de adaptación cultural no deben considerar apenas las diferencias entre los países o sus idiomas, siendo importante que sean ponderados también aspectos relacionados a las realidades local o regional, analizándose en cuanto se gana con la aproximación cultural y en cuanto se pierde con la generalización y la comparabilidad. ${ }^{17}$ Así, apesar del instrumento haber tenido su versión original validada, se optó por la revalidación de la versión en español, una vez que las características de la población objetivo, sus intereses y la naturaleza de la prestación de los servicios de salud pueden ser diferentes entre los países.

Durante el pre test, se observo que las tres enfermeras presentaron dudas en cuanto a los ítems de seguridad del paciente en la administración de medicamentos, como: Utiliza al menos dos identificadores (nombre completo del niño, fecha de nacimiento o número de história clínica) para identificar al niño antes de preparar y administrar medicamentos, en vista que no identificar a los pacientes por su nombre o fecha de nacimiento y priorizar aspectos institucionales, como el número de cama o el contenido biomédico como causa de hospitalización y/o patología, son aspectos que despersonalizan la atención y quizás favorecer la aparición de posibles incidentes y eventos adversos, por tato resulta importante utilizar dos identificadores sugiere la mejora en el conocimiento y seguimiento del equipo de salud combinado con la acción directa de la Seguridad del Paciente en el servicio de pediatría.

Al respecto de eso, se admite no ser aun una rutina de cuidado en los niños hospitalizados en el hospital, pues solo es identificado en la historia clinica ${ }^{18}$ o registro del Kárdex (hoja de registro diario de enfermería donde anota los medicamentos, dosis, frecuencia y la vía de administración y otros tratamientos) ${ }^{19}$ que el enfermero utiliza cada vez que administra medicamento cuando lleva a la cama del niño o lo identifica por el número de cama. 
La Organización Mundial da Salud ${ }^{20}$ preconiza como meta número uno, la identificación correcta del paciente. La identificación del paciente tiene dos propósitos: primero, determinar con seguridad que los niños son destinatarios legítimos del tratamiento; segundo, garantizar que la medicación, cuando es ejecutada, sea efectivamente aquello que el niño necesita. Sin embargo, en la práctica cotidiana se observa que la identificación del paciente aun es una etapa de la asistencia de enfermería todavia no implementada, apesar de las recomendaciones de la OMS, lo que puede no garantizar la calidad y la seguridad de la administración del medicamento. Se resalta que la estratégia de implantar pulseras de identificación, como una de las herramientas para promover un cuidado que priorize la seguridad del paciente, es entendido como una práctica de bajo costo para las instituciones y de fácil instalación en la rutina de atendimiento de los profesionales de salud. ${ }^{21}$

Se destaca, por lo tanto, el papel del enfermero como fundamental por la importancia de la correcta identificación del paciente y su relación con la ocurrencia de errores en la asistencia para la salud del niño.

Se observo también durante el test que el ítem: Realiza doble chequeo de los cálculos de preparación y administración de medicamentos potencialmente peligrosos o medicamentos de alta vigilancia no es una acción que el profesional de enfermería realiza rutinariamente. El doble chequeo es un procedimiento por el cual un segundo profesional de salud verifica el proceso de cálculo de la dosis, en la presencia o ausencia del profesional que realizo el primer chequeo. Se resalta que es uno de los sistemas que permite interceptar errores, pues es muy improbable que dos personas diferentes estén equivocadas en controlar la misma dosis de medicación. Este sistema es aconsejable, en uso de bombas de infusión, cuando medicamentos de alto riesgo son usados para detectar errores en la tasa de infusión. ${ }^{22}$ Por lo que el profesional de enfermería debe fomentar el desempeño de verificaciones dobles para evitar errores que puedan resultar en serios daños a los pacientes.

Se destaca que la experiencia clínica y académica de los jueces permitió un análisis crítico de las estructuras que compone cada ítem, siendo esa evaluación conducida y fundamentada por directrices ya testadas en otros estudios, ${ }^{14,16}$ de modo que las contribuciones y alteraciones sugeridas en el proceso de adaptación posibilitaron el perfeccionamiento de los ítems, llevándose en consideración la seguridad del paciente en la administración de medicamentos en pediatría.

En la dimensión teórica, todos los ítems de la escala obtuvieron más de $50 \%$ de asociación de los ítems evaluados en la versión final con el instrumento original, demostrando congruencia del comité de especialistas en la validación de contenido y opiniones en cuanto a los factores medidos en el instrumento. Los critérios utilizados en esa etapa del estudio demostraron que el Coeficiente de Validad de Contenido de cada ítem (CVCc) total es superior a 0,80 en las tres características evaluadas (pertinencia práctica, clareza y relevancia teórica). En cuanto a los ítems considerados adecuados, se opto por mantener los enunciados y la máxima proximidad con el instrumento original acreditando que esos critérios refinaron el instrumento, permitiendo una mayor comprensión y clareza de los términos utilizados en el instrumento, identificaron puntos fuertes y débiles y favorecieron a las alteraciones con base en las dimensiones teóricas del constructo.

El test de la escala posibilita aún la participación de enfermeras con diferentes tipos de especialización y niveles de experiencias en pediatría, hecho que demostró que el instrumento puede ser comprendido por todas las enfermeras. Se resalta que el título de la escala adoptada en la versión español quedo: "Seguridad del paciente en la administración de medicamentos en Pediatría versión Español (SPAMP-vE)".

Existen limitaciones que deben ser llevados en cuenta. Primero, cómo es mencionado anteriormente, la muestra fue baja en relación al estudio en el cual la versión original fue validada. Segundo realizar la aplicación del instrumento en la prática clínica y su incorporación en actividades rutinarias para la administración de medicamentos en pediatría.

\section{CONCLUSION}

Con base en el objetivo propuesto y resultados obtenidos, se puede concluir que el instrumento Seguridad del paciente en la administración de medicamentos en Pediatría versión Español (SPAMP-vE) se encuentra traducido y adaptado transculturalmente para el español en la realidad cultural del Perú.

Fueron identificadas equivalencias semánticas, idiomática, experimental y conceptual entre los ítems del instrumento original en portugués y la versión final en español. En cuanto a la validación de contenido, o $\mathrm{CVC}_{\mathrm{c}}$ total da escala fue de 0,97 , optándose por mantener los enunciados y la máxima proximidad con el instrumento original.

\section{CONTRIBUCIONES DE LOS AUTORES}

Diseño del estudio. Lilia Jannet Saldarriaga Sandoval.

Recolección y producción de los datos. Sabrina de Souza Gurgel. Igor de Freitas.

Análisis de datos. Francisca Elisângela Teixeira Lima. Lorena Pinheiro Barbosa. Paulo César de Almeida.

Interpretación de los resultados. Lorena Pinheiro Barbosa.

Paulo César de Almeida.

Redacción y revisión crítica del manuscrito. Lilia Jannet Saldarriaga Sandoval. Francisca Elisângela Teixeira Lima. Sabrina de Souza Gurgel. Igor de Freitas. Lorena Pinheiro Barbosa. Paulo César de Almeida.

Aprobación de la versión final del artículo. Lilia Jannet Saldarriaga Sandoval. Francisca Elisângela Teixeira Lima. Sabrina de Souza Gurgel. Igor de Freitas. Lorena Pinheiro Barbosa. Paulo César de Almeida.

Responsabilidad por todos los aspectos del contenido y la integridad del artículo publicado. Lilia Jannet Saldarriaga Sandoval. Francisca Elisângela Teixeira Lima. Sabrina de Souza Gurgel. Igor de Freitas. Lorena Pinheiro Barbosa. Paulo César de Almeida. 


\section{EDITOR ASSOCIADO}

\author{
Candida Primo Caniçali
}

\section{REFERENCIAS}

1. Macedo GPOS, Bohomol E, D'Innocenzo M. Drug therapy for children in emergency hospital service. Acta Paul Enferm. 2015;28(3):237-42. http://dx.doi.org/10.1590/1982-0194201500040.

2. US Food and Drug Administration. Medication error reports [Internet] Silver Spring, MD: FDA; 2019 [citado 2019 mayo 1]. Disponible en: https://www.fda.gov/Drugs/DrugSafety/MedicationErrors/ucm080629. $\mathrm{htm}$

3. Wheeler JS, Duncan R, Hohmeier K. Medication errors and trainees: advice for learners and organizations. Ann. Pharmacother. 2017;51(12):11381141. https://doi.org/10.1177/1060028017725092.

4. Forte ECN, Machado FL, Pires DEP. Nursing's relationship with medication errors: an integrative review. Cogitare Enferm. 2016;21(esp):1-10. http:// dx.doi.org/10.5380/ce.v21i5.43324.

5. Carpenter D, Gonzalez D, Retsch-Bogart G, Sleath B, Wilfond B. Methodological and ethical issues in pediatric medication safety research. Pediatrics. 2017;140(3):e20170195. http://dx.doi.org/10.1542/ peds.2017-0195. PMid:28778857.

6. Silva EC, Damasceno SS, Albuquerque MB, Silva KL, Coutinho SED, Vaz EMC. Administración de medicamentos en pediatría: sentimientos experimentados de la teoría a la práctica académica. Rev enferm UFPE. 2013;7048;54. http://dx.doi.org/10.5205/reuol.4767-42136-1ED.0712esp201312.

7. Carrasco FJA, Diaz MRJ, Rodríguez CLD, Sonia TM, Sánchez CMJ Sistema de seguridad en la administración de fármacos en servicios pediátricos hospitalarios. Rev Cubana Pediatr. 2020;92(3):e961.

8. Lacasa C, Ayestarán A. Estudio multicéntrico español para la Prevención de Errores de Medicación. Resultados de cuatro años (2007-2011). Rev. Farm Hosp. 2012;36(5):356-67. http://dx.doi.org/10.1016/j. farma.2011.10.002.

9. Organizacao Mundial da Saude. Marco Conceptual da Classificação Internacional para a Seguridade do Paciente [Internet]. Genebra, Suíça: OMS; 2009 [citado 2016 mayo 4]. Disponible en: http://www.who.int/ patientsafety/implementation/icps/icps_full_report_es.pdf

10. Sánchez Herrero M. Errores de medicación de la enfermería en el ámbito hospitalario Revisión bibliográfica [tesis]. Valladolid, Espanha: Universidad de Valladolid; 2016 [citado 2016 mayo 4]. Disponible en: https://uvadoc.uva.es/bitstream/10324/25115/1/TFG-L1597.pdf
11. Truter A, Schellack N, Meyer J C. Identifying medication errors in the neonatal intensive care unit and paediatric wards using a medication error checklist at a tertiary academic hospital in Gauteng, South Africa. S Afr j Child Health. 2017;11(1):5-10. http://dx.doi.org/10.7196/sajch.2017. v11i1.1101.

12. Araújo PR, Lima F, Ferreira MKM, Oliveira SKP, Carvalho REFL, Almeida PC. Medication administration safety assessment tool: construction and validation. Rev Bras Enferm. 2019;72(2):329-36. http://dx.doi org/10.1590/0034-7167-2018-0340. PMid:31017193.

13. Macedo T, Rocha PK, Tomazoni A, Souza S, Anders JC, Davis K. The culture of patient safety from the perspective of the pediatric emergency nursing team. Rev Esc Enferm USP. 2016;50(5):756-62. http://dx.doi. org/10.1590/s0080-623420160000600007. PMid:27982393.

14. Beaton D, Bombardier C, Guillemin F, Ferraz MB. Recommendations for the Cross-Cultural Adaptation of the DASH \& QuickDASH Outcome Measures. [S.I.]: Institute for Work \& Health; 2007.

15. Lobiondo-Wood G, Haber, J. Nursing Research; Methods and Critical Appraisal for Evidence-Based Practice. 9th ed. St. Louis Missouri. Elsevier; 2018.

16. Pasquali L. Psicometria:Teoría dos testes na psicología e na educação. Petrópolis: Vozes; 2017

17. Araújo PR, Lima FET, Ferreira MKM, Oliveira SKP, Carvalho REFL, Almeida PC. Instrumento para avaliação da segurança na administração de medicamentos: construção e validação. Rev Bras Enferm. 2019 marzo-abr;72(2):329-36. http://dx.doi.org/10.1590/0034-7167-20180340. PMid:31017193.

18. De Souza RFF, Da Silva LD. Estudo exploratório das iniciativas acerca da segurança do paciente em hospitais do Rio de Janeiro. Revista Enfermagem UERJ. 2014;22(1):22-8.

19. Castro I, Gámez M. Historia clínica. Rev. Farmacia Hospitalaria [Internet] 2015. [citado 20 mar 2018];22(1): 295-306. Disponible en: https://www. sefh.es/bibliotecavirtual/fhtomo1/cap22.pdf

20. Organizacion Mundial de la Salud. Estudio IBEAS Red pionera en la seguridad del paciente en Latinoamerica. Hacia una atención hospitalaria màs segura. Ginebra, Suiza: OMS; 2010.

21. Hoffmeister L, Moura G. Use of identification wristbands among patients receiving inpatient treatment in a teaching hospital. Rev Lat Am Enfermagem. 2015;23(1):36-43. http://dx.doi.org/10.1590/01041169.0144.2522. PMid:25806629.

22. BRASIL. Ministério da Saúde. Anvisa. Fiocruz. Fleming. Anexo 03 Protocolo de segurança na prescrição, uso e administração de medicamento. Brasília, DF. Ministério da Saúde; 2013. [citado 10 mar 2019]. Disponible en: http://www.anvisa.gov.br 